\title{
Inadvertent Stent Retriever Detachment: A Multicenter Case Series and Review of Device Experience FDA Reports
}

\author{
Hesham Masoud $^{a} \quad$ Thanh N. Nguyen $^{b} \quad$ Coleman O. Martin ${ }^{c}$ \\ William E. Holloway ${ }^{c}$ Sudheer Ambekare Dileep R. Yavagale \\ Diogo C. Haussen $^{f}$ Raul Nogueira ${ }^{f}$ Diego J. Lozano ${ }^{g}$ Ajit Puri ${ }^{g}$ \\ Ayman Quateen' Daniela Iancu' Michael G. Abraham ${ }^{d}$ Michael Chen ${ }^{\text {h }}$ \\ Sonal Mehta ${ }^{i}$ Tim Malisch $^{j}$ Franklin Marden ${ }^{j}$ Robin Novakovick \\ Daniel Roy ${ }^{\mathrm{m}} \quad$ Alain Weill $^{\mathrm{m}} \quad$ Alexander M. Norbash ${ }^{\mathrm{b}}$

\begin{abstract}
a SUNY Upstate Medical University, Syracuse, N.Y., ${ }^{b}$ Boston University School of Medicine, Boston, Mass., 'University of Missouri at Kansas City, St. Luke's Health System, and dUniversity of Kansas School of Medicine, Kansas City, Kans., e University of Miami Miller School of Medicine, Miami, Fla., ${ }^{f}$ Emory University School of Medicine, Atlanta, Ga., g University of Massachusetts, Worcester, Mass., h Rush University Medical Center, Chicago, Ill., iUniversity Specialty Clinics, University of South Carolina, Columbia, S.C.,

jAlexian Brothers Medical Center, Elk Grove Village, Ill., and kUT Southwestern Medical Center, Dallas, Tex., USA; 'University of Ottawa, Ottawa, Ont., and ${ }^{\mathrm{m}}$ Centre Hospitalier de I'Université de Montréal, Montreal, Ont., Canada
\end{abstract}

\section{Key Words}

Stroke $\cdot$ Stent retriever $\cdot$ Trevo device $\cdot$ Solitaire FR device $\cdot$ Mechanical thrombectomy · Detachment

\begin{abstract}
Mechanical thrombectomy using retrievable stents or stent retriever devices has become the mainstay of intra-arterial therapy for acute ischemic stroke. The recent publication of a series of positive trials supporting intra-arterial therapy as standard of care for the treatment of large vessel occlusion will likely further increase stent retriever use. Rarely, premature stent detachment during thrombectomy may be encountered. In our multicenter case series, we found a rate of detachment of less than $1 \%(n=7 / 1,067)$, and all were first-generation Solitaire FR devices. A review of the US Food and Drug Administration database of device experience yielded 90 individual adverse reports of detachment. There were 82, 1 and 7 detachments of Solitaire FR (first generation), Solitaire FR2 (second generation) and Trevo devices, respectively. We conclude with a brief overview of the technical and procedural considerations which may be helpful in avoiding this rare complication.




\section{Introduction}

There are several techniques which can be employed in the endovascular management of acute ischemic stroke (AIS). A recent analysis of the National and Nationwide Inpatient Sample showed an increased trend toward the utilization of mechanical thrombectomy and a decline in mortality following its use [1]. Mechanical thrombectomy has emerged as the main treatment for large vessel occlusion, in addition to intravenous therapy in eligible patients. A variety of devices are available to this end. Most recently, the use of retrievable stents or stent retrievers has become the mainstay of intra-arterial (IA) therapy for AIS [2].

Initially designed as detachable stents for aneurysm coiling, the potential for thrombectomy was realized through off-label use. Stent retriever deployment within the target clot of an occluded vessel results in entrapment of the thrombus by the stent struts. The stent is then withdrawn into a proximal catheter, and the enmeshed thrombus is extracted from the vessel.

In 2012, the US Food and Drug Administration (FDA) granted market clearance to two stent retriever devices after the reported results of the SWIFT and TREVO 2 trials, which demonstrated that stent retrievers had superior recanalization rates and improved functional outcome compared to the MERCI Retriever device (Concentric Medical, Mountain View, Calif., USA) [3, 4].

The MR CLEAN trial was the pivotal trial reporting improved outcomes with IA therapy compared to standard medical care in AIS. Stent retriever devices were used in $81.5 \%$ of patients assigned to the endovascular treatment group in this trial [5]. The recent results of other IA trials using stent retriever devices further support endovascular therapy as the standard of care in AIS [6-9]. The reported rates of complications for stent retriever mechanical thrombectomy are low. Commonly reported complications include blood vessel injury, embolization to a new vascular territory and symptomatic intracranial hemorrhage. Although not included in any of the published IA stent retriever thrombectomy trials, the complication of stent detachment has also been reported [10]. It is likely that demand for IA therapy and the subsequent use of stent retrievers are on the rise [11]. As such, the potential for device-related procedural complications is important for any stroke interventionalist to consider.

We present a multicenter study of stent retriever detachments and the results of an online search of the FDA device experience database for reports of inadvertent stent retriever detachment. A review of the literature for similar cases is also provided. To conclude, we make a brief technical note which may serve to prevent this rare complication.

\section{Methods}

From January 2012 to March 2015, we reviewed consecutive cases of stent retriever thrombectomy performed at 11 centers in the USA and Canada. The number of stent retriever detachments per total number of stent retriever thrombectomy cases was recorded. When available, the operators provided a brief description of the circumstances that led to stent retriever device separation. Our study was approved by the institutional review board at each site when applicable. A search of the FDA Manufacturer and User Facility Device Experience (MAUDE) database was also conducted for reports of stent retriever experience from January 1, 2012, to December 31, 2014. The MAUDE database houses mandatory and voluntarily submitted medical device reports from August 1996 to the present [12]. The search was performed using the search terms 'Solitaire FR' and 'Trevo'. Each FDA report was reviewed for mention of stent detachment, separation or fracture. When available, procedural details and timing of detachment were recorded. 
Fig. 1. Successful retrieval of a detached thrombus-laden stent retriever using a MERCI Retriever device in a 62-year-old man presenting with right middle cerebral artery syndrome (NIHSS score 15). After successful proximal carotid artery stenting and mechanical thrombectomy, the $4 \times 20 \mathrm{~mm}$ Solitaire FR device detached above the carotid stent.

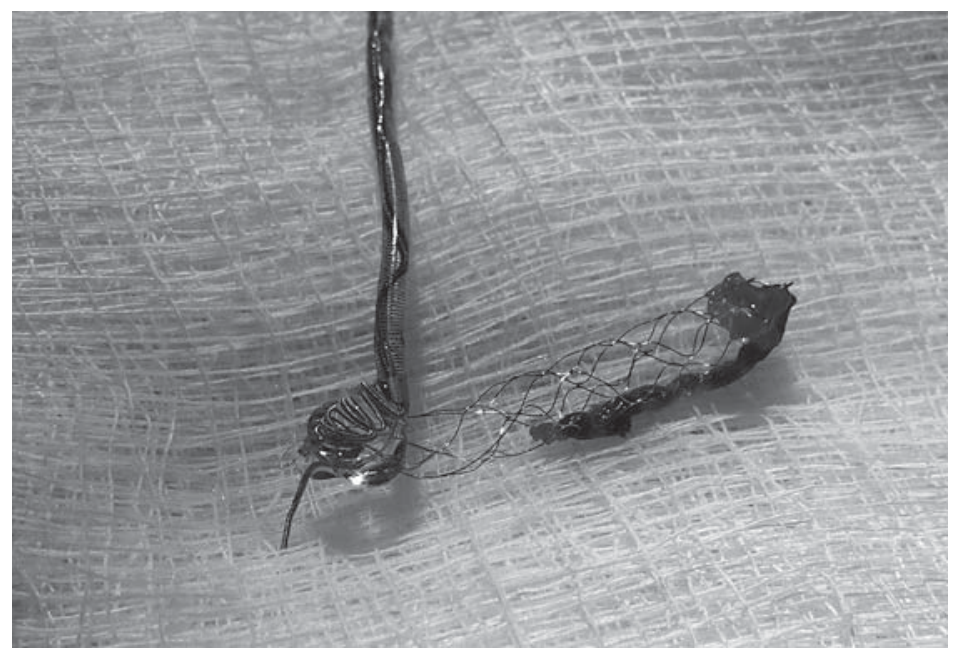

Table 1. Stent retriever detachment patient characteristics

\begin{tabular}{llllllll}
\hline $\begin{array}{l}\text { Patient } \\
\text { No. }\end{array}$ & Device & $\begin{array}{l}\text { Number of } \\
\text { thrombectomy } \\
\text { passes with } \\
\text { a single device }\end{array}$ & $\begin{array}{l}\text { Age, } \\
\text { years }\end{array}$ & Sex & $\begin{array}{l}\text { Baseline } \\
\text { NIHSS } \\
\text { score }\end{array}$ & $\begin{array}{l}\text { Location } \\
\text { of occlusion }\end{array}$ & $\begin{array}{l}\text { Patency of } \\
\text { vessel after } \\
\text { detachment }\end{array}$ \\
\hline 1 & Solitaire FR & 2 & 49 & M & 18 & MCA & no \\
2 & Solitaire FR & 2 & 85 & F & 19 & MCA & no \\
3 & Solitaire FR & 1 & 77 & F & 22 & MCA & no \\
4 & Solitaire FR & 2 & 62 & M & 15 & MCA & yes \\
5 & Solitaire FR & 1 & n.a. & n.a. & n.a. & VERT & yes \\
6 & Solitaire FR & 2 & n.a. & n.a. & n.a. & n.a. & n.a. \\
7 & Solitaire FR & 3 & 86 & F & 23 & MCA & yes \\
\hline
\end{tabular}

M = Male; F = female; n.a. = not assessed; MCA = middle cerebral artery; VERT = vertebral artery.

\section{Results}

In our study, there were a total of 1,067 cases of stent retriever mechanical thrombectomy. Stent retriever detachment occurred in 7 patients $(0.66 \%)$. The characteristics of the patients are provided in table 1 . Two of the detachments were attributed to device ensnarement in an existing stent during attempted device retrieval. One device was successfully recovered using a second mechanical thrombectomy device (fig. 1).

The FDA MAUDE database search yielded 166 individual reports of adverse stent retriever device experience (fig. 2). Limited information was available regarding procedural details, management and outcome. Stent detachment was documented in 90 reports (54\%). There were 97 reports of first-generation Solitaire FR device experience, and 82 detachments were described; 6 detachments were attributed to entanglement in a more proximal stent. The timing of detachment (in regard to the number of attempted retrieval passes) was documented in 28 reports (fig. 3); 13 reports included mention of attempts to remove the detached stent, employing a wide range of techniques: use of a micro-snare device, manual aspiration and a second mechanical thrombectomy device. 
Fig. 2. Number of MAUDE database entries by stent retriever device.

Fig. 3. Stent retriever device detachments by number of retrieval passes.
Masoud et al.: Inadvertent Stent Retriever Detachment: A Multicenter Case Series and Review of Device Experience FDA Reports
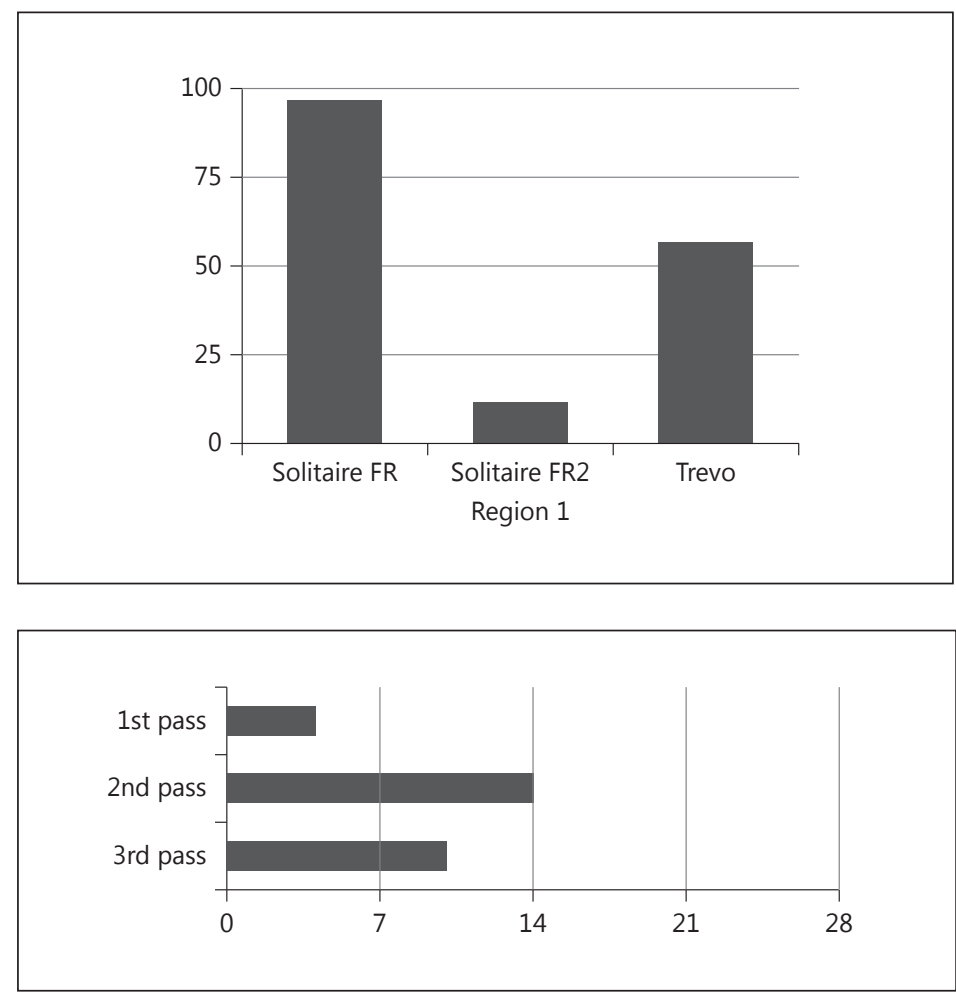

There were 12 second-generation (Solitaire FR2) device reports, and 1 detachment was reported. This was attributed to stent separation when the device was caught in the balloon guide catheter during retrieval.

Our search of the MAUDE database for the Trevo device yielded 64 records, narrowed down to 57 unique reports. In these, stent detachment or fracture was documented for 7 patients $(12.3 \%)$. There were 5 reports of Trevo device detachment attributed to device entanglement in a proximal carotid stent.

Among the total of 166 reports, there was 1 extracorporeal stent retriever detachment, resulting from the selection of an inadequately sized microcatheter. In the MAUDE database, the percentages of medical reports related to detachment by stent retriever device were: Trevo, 12.3\% ( $n=7 / 57)$; Solitaire FR, 84.5\% $(n=82 / 97)$, and Solitaire FR2, 8.3\% $(n=1 / 12)$.

\section{Discussion}

Our cases of detachment featured the original Solitaire FR, the first stent retriever device to gain FDA approval. The Solitaire FR was initially developed for use in intracranial aneurysm treatment, designed for precise stent placement to bridge wide-necked aneurysms for coiling, and features a detachment zone permitting electrolytic, controlled detachment after deployment. However, the device's relatively low radial force, high flexibility, thin wall and ability to be retrieved and repositioned allowed its use in thrombus retrieval [13].

The Trevo XP ProVue device (Stryker Neurovascular, Fremont, Calif., USA) was developed for thrombectomy in AIS, featuring broad stent struts with an endoluminal orientation for optimal thrombus interaction. The device is radiopaque for easier visualization during deployment and retrieval [14]. 
Masoud et al.: Inadvertent Stent Retriever Detachment: A Multicenter Case Series and Review of Device Experience FDA Reports
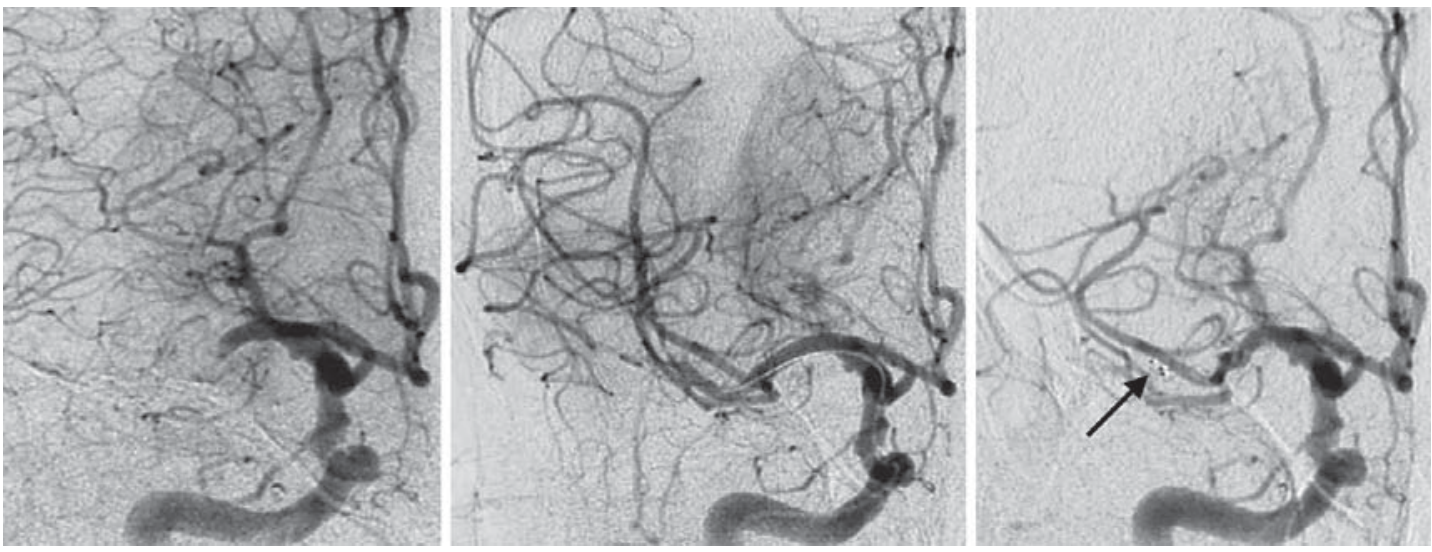

Fig. 4. Right internal carotid artery angiography (ICA; anteroposterior projection) of an 86-year-old woman presenting with right middle cerebral artery (MCA) syndrome (NIHSS score 23). The images (from left to right) demonstrate right ICA angiography showing proximal MCA occlusion, the third deployment of a $4 \times 20$ $\mathrm{mm}$ Solitaire FR device and subsequent detachment (arrow) of the stent retriever in the proximal MCA with persistent branch occlusion.

Our multicenter case series of consecutive stent retriever thrombectomies yielded a low rate of stent retriever detachment $(0.66 \%)$. Operator reporting of device experience in the MAUDE database is voluntary and therefore unlikely to include all events of stent detachment. Even accounting for the possibility of underreporting, stent retriever detachment appears to be a rarely encountered complication. A retrospective multicenter analysis of early postmarket experience with the Solitaire FR device disclosed no instances of device detachment [15]. Furthermore, events of stent detachment were not collected in the North American Solitaire Stent Retriever Acute Stroke (NASA) or TREVO Stent-Retriever Acute Stroke (TRACK) registries $[16,17]$.

There is scant literature on the premature detachment of stent retriever devices. Few publications on device experience report incidence rates of stent detachment. Gascou et al. [10] reported 2 stent detachments in 144 cases of mechanical thrombectomy. Both stents were left in place and managed conservatively with long-term antiplatelet therapy. Dorn et al. [18] shared their single-center experience with the Solitaire FR device in 108 recanalization procedures, reporting only 1 instance of stent retriever detachment. Another report of 26 patients disclosed 2 detachments, with 1 reportedly due to stent retriever entanglement in a proximal carotid stent [19].

\section{Technical Considerations}

A brief review of stent retriever deployment techniques and the contributing factors that may have led to detachment in our case may help others avoid this complication in the future. The stent retriever device is introduced after positioning of the delivery microcatheter distal to the occlusive thrombus. The stent retriever is then deployed into the clot by unsheathing the microcatheter.

In our center's case (fig. 4), the delivery microcatheter may have been inadequately anchored over the detachment zone on the final pass, possibly contributing to the stent detachment. It has been suggested that prolonged exposure of the detachment zone to the blood stream may result in weakening by activating an electrochemical detachment process [20]. 
Kwon et al. [21] conducted an in vitro study of 5 Solitaire FR stent retrievers deployed under different conditions and measured the tensile force required for stent separation. A microscopic evaluation of the devices showed separation in or around the proximal marker, not at the detachment zone.

The manufacturer's instructions for use (IFU) recommend re-sheathing the proximal marker prior to Solitaire FR device retrieval, presumably to lower the risk of separation, although a case of detachment despite these instructions has been reported [22].

Device fatigue may have contributed to our stent detachment, which occurred on the third attempted pass. When reported in the MAUDE database, $26.6 \%(n=24 / 90)$ of total detachments occurred on attempts performed after the first pass. Intuitively, with each device deployment and retrieval, stent retriever fatigue and a resultant increased risk for device detachment are likely. Adherence to the manufacturer's IFU, i.e. limiting the number of single Solitaire FR device passes to 2, may help attenuate this risk. This is especially relevant with the first-generation Solitaire FR device, as well as in patients with tortuous anatomy and calcified vessels, where an increased forward force necessary to position the stent retriever may cause excessive bending of the stent. The Trevo XP ProVue device was not manufactured as a detachable stent, and the IFU warning limits its use to 6 retrieval attempts per target vessel.

An oversized or fully deployed stent can be more resistant to being pulled back due to an increased radial force on the vessel wall, requiring greater force to retrieve the stent, which can contribute to breakage of the push wire. Incomplete unsheathing of the Solitaire FR device has been advocated as a way to minimize this risk, but this may also result in less successful clot retrieval due to a decreased clot-stent interface [20]. However, new and longer stent retriever devices are now available, permitting an increased length of the clot-stent interface. It is worth noting that it is unknown whether stent retriever detachment is more common or less common with the longer devices.

In our review of the MAUDE database, the majority of the reported device detachments were seen with the first-generation Solitaire FR (fig. 2). This is a by-product of being the first stent retriever in the market and therefore representing the main part of stent retriever device experience to date.

The second-generation Solitaire device (Solitaire FR2) was given clearance in January 2014 and fully released to the market by June 2014. Unlike the first-generation device, this newer iteration is not detachable. It also features several refinements on the original device to reduce delivery friction, including a redesigned distal push wire offering a reduction in retrieval force. These improvements in design are likely to reduce the risk of premature detachment.

A minority of AIS patients may present with tandem arterial occlusions. Some may require deployment of a proximal carotid stent prior to stent retriever thrombectomy of the distal clot [23]. In our study, we noticed a number of reports of device detachment attributed to entanglement in a proximal stent. To avoid this, it may be useful to attempt to reposition the guide catheter through the proximal stent prior to retrieval, thus reducing the risk of entanglement. However, care must be taken not to dislodge the proximal stent while advancing the guide catheter through it. Another alternative is to use balloon angioplasty for the proximal occlusion just enough to permit adequate flow or access to the distal occlusion, and not deploy a proximal stent if this can be avoided.

\section{Management}

Management of this rare complication may include attempts to retrieve the detached stent. Successes using a second stent retriever device to capture the detached stent have been reported [22]. A novel use of the Trevo device in foreign-body recovery of migrated coils is 
also described [24, 25]. However, the risk-benefit profile of such a technique must be taken into consideration. Dragging of the stent through the vasculature may lead to further procedural complications such as arterial dissection, vasospasm and vessel perforation.

Alternatively, the detached stent retriever may be extracted surgically [26] or left in place if the vessel remains open. Balloon angioplasty of the stent may be helpful in this regard. Subsequent in-stent thrombosis and propagation of thrombus can develop and may necessitate the intraoperative use of GIIb/IIIa inhibitors, which can increase the risk of intracranial hemorrhage in acute stroke [27].

As with any implanted intracranial stent, postoperative dual antithrombotic therapy (aspirin and Plavix) is recommended to prevent delayed thrombosis of the detached stent retriever. However, as encountered in our case, starting this therapy may be difficult in the acute setting if the patient has received intravenous tissue plasminogen activator. This may require a delay in the initiation of antiplatelet medication by at least $24 \mathrm{~h}$ to guard against the risk of symptomatic intracranial hemorrhage.

\section{Conclusions}

Stent retriever detachment during mechanical thrombectomy appears to be a rare complication of AIS management. Push wire fatigue and device retrieval through a proximally stented artery were most often cited as causes. Attempts to recover a detached stent should be weighed against the possibility of causing further complications.

\section{Disclosure Statement}

The authors have no conflicts of interest to report.

\section{References}

1 Villwock MR, Padalino DJ, Deshaies EM: Trends in mortality following mechanical thrombectomy for the treatment of acute ischemic stroke in the USA. J Neurointerv Surg 2015, Epub ahead of print.

$\checkmark 2$ Campbell BCV, Donnan GA, Lees KR, et al: Endovascular stent thrombectomy: the new standard of care for large vessel ischaemic stroke. Lancet Neurol 2015;14:846-854.

-3 Saver JF, Jahan R, Levy EI, Jovin TG, Baxter B, Nogueira RG, Clark W, Budzik R, Zaidat O0; SWIFT Trialists: Solitaire flow restoration device versus the Merci Retriever in patients with acute ischemic stroke (SWIFT): a randomised, parallel-group, non-inferiority trial. Lancet 2012;380:1241-1249.

-4 Nogueira RG, Lutsep HL, Gupta R, Jovin TG, Albers GW, Walker GA, Liebeskind DS, Smith WS; TREVO 2 Trialists: Trevo versus Merci retrievers for thrombectomy revascularisation of large vessel occlusions in acute ischaemic stroke (TREVO 2): a randomised trial. Lancet 2012;380:1231-1240.

5 Berkhemer OA, Fransen PA, Beumer D, et al: A randomized trial of intraarterial treatment for acute ischemic stroke. N Engl J Med 2015;372:11-20.

6 Goyal M, Demchuk AM, Menon BK, et al; ESCAPE Trial Investigators: Randomized assessment of rapid endovascular treatment of ischemic stroke. N Engl J Med 2015;372:1019-1030.

-7 Campbell BC, Mitchell PJ, Kleinig TJ, et al; EXTEND-IA Investigators: Endovascular therapy for ischemic stroke with perfusion-imaging selection. N Engl J Med 2015;372:1009-1018.

-8 Saver JL, Goyal M, Bonafe A, et al; SWIFT PRIME Investigators: Stent-retriever thrombectomy after intravenous t-PA versus t-PA alone in stroke. N Engl J Med 2015;372:2285-2295.

-9 Jovin TG, Chamorro A, Cobo E, et al; REVASCAT Trial Investigators: Thrombectomy within $8 \mathrm{~h}$ after symptom onset in ischemic stroke. N Engl J Med 2015;372:2296-2306.

$\checkmark 10$ Gascou G, Lobotesis K, Machi P, Maldonado I, Vendrell JF, Riquelme O, et al: Stent retrievers in acute ischemic stroke: complications and failures during the perioperative period. Am J Neuroradiol 2014;35:734-740.

11 Donnan GA: The impact of MR CLEAN. Int J Stroke 2015;10:139.

12 FDA: Medical device reporting, MAUDE database. http://www.fda.gov/MedicalDevices/Safety/ReportaProblem (retrieved online February 5, 2015). 
Masoud et al.: Inadvertent Stent Retriever Detachment: A Multicenter Case Series and

13 Castaño C, Serena J, Dávalos A: Use of the new Solitaire ${ }^{\mathrm{TM}}$ AB device for mechanical thrombectomy when Merci Clot Retriever has failed to remove the clot. A case report. Interv Neuroradiol 2009;15:209-214.

14 Nogueira RG, Levy EI, Gounis M, Siddiqui AH: The Trevo device: preclinical data of a novel stroke thrombectomy device in two different animal models of arterial thrombo-occlusive disease. J Neurointerv Surg 2012; 4:295-300.

15 Mokin M, Dumont TM, Veznedaroglu E, Binning MJ, Liebman KM, et al: Solitaire FR thrombectomy for acute ischemic stroke: retrospective multicenter analysis of early postmarket experience after FDA approval. Neurosurgery 2013, Epub ahead of print.

16 Zaidat 00, Castonguay AC, Gupta R, et al: North American Solitaire Stent Retriever Acute Stroke registry: postmarketing revascularization and clinical outcome results. J Neurointerv Surg 2014;6:584-588.

$\checkmark 17$ Zaidat 0, Castonguay A, Veznedaroglu E, et al: P-021 TREVO Stent-Retriever Acute Stroke (TRACK) PostMarketing Registry: interim revascularization and clinical outcome results compared to TREVO-2 and NASA Registry. J Neurointerv Surg 2014;6(suppl 1):A31-A32.

18 Dorn F, Stehle S, Lockau H, Zimmer C, Liebig T: Endovascular treatment of acute intracerebral artery occlusions with the Solitaire stent: single-centre experience with 108 recanalization procedures. Cerebrovasc Dis 2012;34:70-77.

19 Miteff F, Faulder KC, Goh ACC, Steinfort BS, Sue C, Harrington TJ: Mechanical thrombectomy with a selfexpanding retrievable intracranial stent (Solitaire $\mathrm{AB}$ ): experience in 26 patients with acute cerebral artery occlusion. AJNR Am J Neuroradiol 2011;32:1078-1081.

-20 Youn SW, Kim HK: Refinement of a thrombectomy technique to treat acute ischemic stroke: technical note on microcatheter advance during retrieving self-expandable stent. J Korean Soc Radiol 2012;67:1-6.

21 Kwon HJ, Chueh JY, Puri AS, Koh HS: Early detachment of the Solitaire stent during thrombectomy retrieval: an in vitro investigation. J Neurointerv Surg 2015;7:114-117.

-22 Akpinar S, Yilmaz G: Spontaneous Solitaire ${ }^{\mathrm{TM}} \mathrm{AB}$ thrombectomy stent detachment during stroke treatment. Cardiovasc Intervent Radiol 2015;38:475-478.

-23 Heck DV, Brown MD: Carotid stenting and intracranial thrombectomy for treatment of acute stroke due to tandem occlusions with aggressive antiplatelet therapy may be associated with a high incidence of intracranial hemorrhage. J Neurointerv Surg 2015;7:170-175.

24 Liu KC, Ding D, Starke RM, Geraghty SR, Jensen ME: Intraprocedural retrieval of migrated coils during endovascular aneurysm treatment with the Trevo Stentriever device. J Clin Neurosci 2014;21:503-506.

25 Kabbani MR, Smith A, Leider M: Endovascular coil retrieval using a TrevoProVue stentriever. BMJ Case Rep 2014;2014:bcr2014011181.

26 Kang DH, Park J, Hwang YH, Kim YS: Inadvertent self-detachment of Solitaire AB stent during the mechanical thrombectomy for recanalization of acute ischemic stroke: lessons learned from the removal of stent via surgical embolectomy. J Korean Neurosurg Soc 2013;53:360-363.

27 Adams H, Effron M, Torner J, et al: Emergency administration of abciximab for treatment of patients with acute ischemic stroke: results of an international phase III trial: AbESST-II. Stroke 2008;39:87-99.

\section{Erratum}

In the article by Masoud et al., entitled 'Inadvertent stent retriever detachment: a multicenter case series and review of device experience FDA reports ' [Intervent Neurol 2015;4:75-82, DOI: 10.1159/000441920], the first name of the 11th co-author Quateen needs to be corrected to Aiman. 